\title{
DOCUMENTING THE ARCHITECTURAL CHARACTERISTICS OF CATHEDRAL CHURCH OF RESURRECTION, LAHORE
}

\author{
Faiqa Khilat* \\ Dr. Muhammad Yusuf Awan** \\ Sana Malik*** \\ Beenish Mujahid****
}

\begin{abstract}
The Cathedral Church of the Resurrection is a spectacular, monumental structure having distinctive features of Gothic architecture located on Mall Road, Lahore. In the nineteenth century, British rulers developed this road as the foremost city centre after they established their government in the area. Other important buildings situated on this road are High Court, General Post Office, Town Hall, Montgomery Hall, Punjab University, Atchison College, churches and cathedrals. Among various structures, the enormity of this Cathedral reflects its glory in cosmic green meadows. The artistic style of Gothic architecture introduced by the British is truly represented in this monument. Every day, many Christians visit this church to perform their sacramental obligations. In addition, the Cathedral includes a missionary school, known as Lahore Cathedral School. The structure seems to be intact, but a closer examination reveals the reality of major aspects in need of attention. This research was carried out by closely scrutinizing numerous fragments of the Cathedral through surveys and photographic documentation. This paper highlights the distinct character of the monument by assessing its architectural features in detail and concluding various measures needed to conserve the monument's heritage.
\end{abstract}

Keywords: Gothic, architecture, church, monument, Cathedral

\section{INTRODUCTION}

The city of Lahore was conquered by the British in mid nineteenth century which was when the city spread outside the Mughal's Walled City of Lahore (Figure 1). Considering the potential of the city, the British introduced new building typology and architecture in the city in terms of educational institutions, railroads, shopping malls, museums, courts, churches, and cathedrals (Glover, 2011).

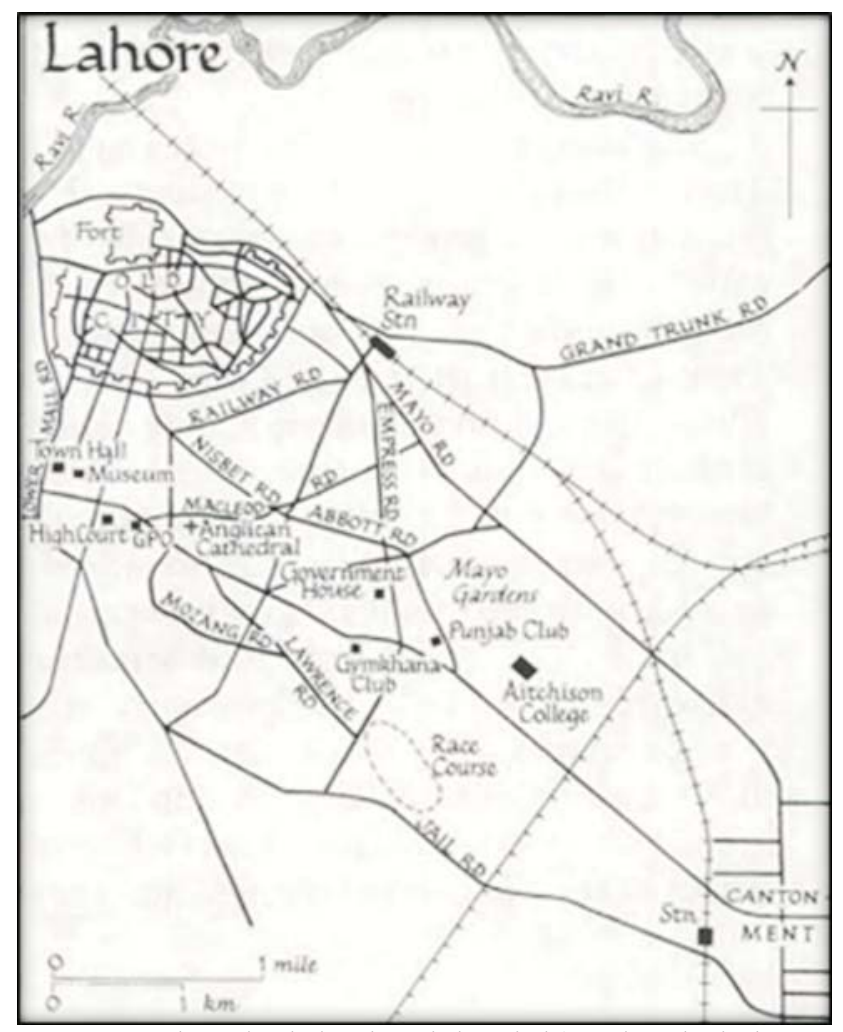

Figure-1: Lahore city during the Britsh Period (Morris and Winchester, 2008).

\footnotetext{
* $\quad$ Faiqa Khilat, Assistant Professor, School of Architecture and Planning, University of Management of Technology, Lahore. Email correspondance: faiqa.khilat@umt.edu.pk

** Dr. Muhammad Yusuf Awan, Professor, School of Architecture and Planning, University of Management of Technology, Lahore. Email correspondance: yusuf.awan@umt.edu.pk

*** Sana Malik, Assistant Professor, School of Architecture and Planning, University of Management of Technology, Lahore. Email correspondance: sana.malik@umt.edu.pk

$* * * *$ Beenish Mujahid, Lecturer, School of Architecture and Planning, University of Management of Technology, Lahore. Email correspondance: beenish.mujahid@umt.edu.pk
} 
Today many significant architectural edifices of British rule can be found in the city of Lahore. The British mixed the Mughal and British construction styles known as the AngloMughal style, or hybrid style. Many examples of this style still exist in Lahore, most prominent of which are Bank of Bengal, Central Post Office, Punjab Club, Supreme Court, Department of Public Works, Government College Lahore, Central Model School, Lahore Museum, University of Punjab, Tollinton Market and Town Hall. Pictorial representation of these buildings is shown in Table 1. Moreover, the grand structure of the Cathedral Church of the Resurrection was built in the Neo-Gothic style. The residents of Lahore commonly refer to the Cathedral Church as Kukar Girja because of a weather cock that was mounted on the top of the Cathedral.

Today, the Cathedral Church of the Resurrection, Lahore, is the centre of the Lahore Diocese, which was carved out of the Diocese of Calcutta, the largest Anglican diocese in South Asia, in 1877, which included the area up to Delhi,
East Punjab, Kashmir, Afghanistan, with some responsibility for the southern states of the Persian Gulf (Aijazuddin, 2004).

Among all the other cathedrals of Lahore, this magnificent structure is an example of Gothic architecture, which resembles cathedrals found in Europe, specifically the Norte Dame and Charte Cathedrals in France. The Cathedral is a unique illustration of purely Neo-Gothic features, portraying an enormous monument standing on the ground with pointed arches, flying buttresses lancet and stained glass windows. These splendid structures and their architecture are tourist attractions. The conservation of these monuments is necessary to enhance their value. The building should be preserved in order to withstand future hazards which could cause its decay in any manner. This research aims to document this significant heritage structure before it loses its original form. It highlights and identifies the history, the existing condition and various architectural features of the historic edifice.

Table-1: Renowned Edifices Constructed on Mall Road, Lahore, during the British Period (Punjab University to Punjab Assembly)

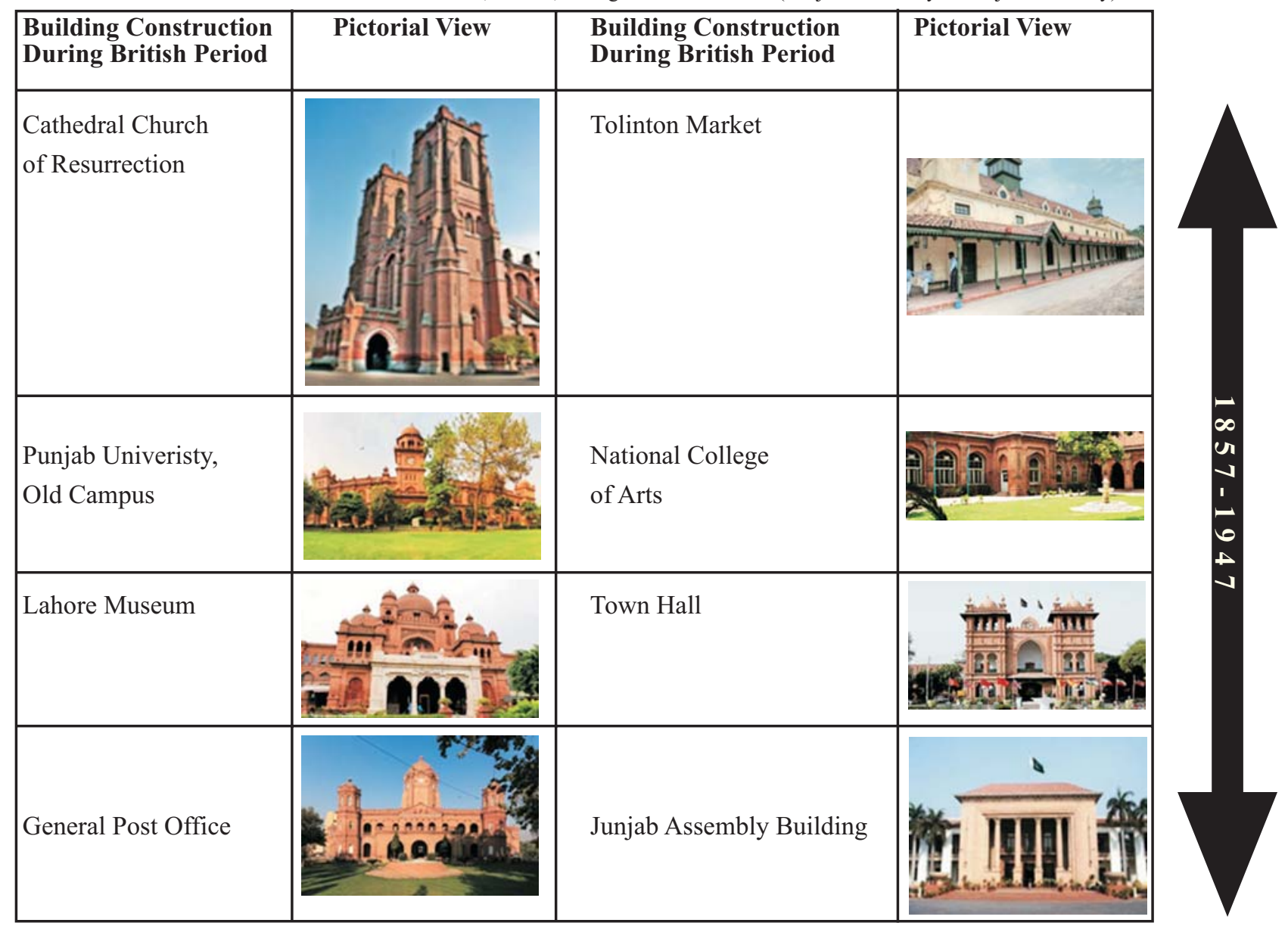




\section{Selection of Case Study}

The selection of the case study is based on its regional context and architectural value. Since Pakistan's independence, the construction of cathedrals has been restricted as they are a religious symbol of the Christian community, one of the country's minorities. Although this Cathedral premises contains other important historical buildings, such as the Government College University (GCU), this particular building is in a constant state of neglect. Since buildings of such nature are non-profitable, they are excluded from development plans and policies at a national level.

\section{Location}

The Cathedral Church of the Resurrection is located on the Mall Road, just opposite the Lahore High Court. The Cathedral is also adjacent to McLeod Fane Road. All of these roads have a continuous flow of traffic causing noise. Inside the site is a green lawn with dense vegetation, and the eye-catching monument of the Cathedral of the Resurrection (Figure 2).

\section{RESEARCH METHODOLOGY}

The qualitative research was carried out by detailed surveys of the site and an interview with the supervisor of the Cathedral. The research was further substantiated by review of relevant literature. International cathedrals were also studied in regard to Gothic architecture to compare them to Lahore heritage. Furthermore, the structure of the Cathedral Church of the Resurrection was analyzed, and conclusions were drawn for physical improvement and conservation of the monument.

\section{LITERATURE REVIEW}

\section{Gothic Architecture}

Gothic Architecture was developed in Western Europe in about $1150 \mathrm{AD}$ to $1500 \mathrm{AD}$ as a distinctive style due to its features. It originated in France and spread throughout the rest of Europe, including countries like England, Germany, and Spain (Gosh, 2010), during the time known as the Medieval Period. It originated from Romanesque Architecture and prospered through Renaissance Architecture. The master builders produced new building techniques and projects. The widespread competition between monasteries and bishops for this style of cathedrals played an instrumental role in the culmination of Gothic Architecture. Its fundamental characteristic was its height, and general features included the pointed arch, the ribbed vault and the flying buttresses (Wilson, 1992). Internationally, the Lahore Cathedral can be compared to other English and French Cathedrals as shown in Table 2 (Fletcher, 1994).

Another example of Gothic Architecture in the sub-continent is the The Lady of Dolours Church, located in Thrissur, Kerala, India (Figure 3)(Vadakkekara, 2007). This Church is one of the largest churches in India and is known for its

Table-2: International Gothic Style Cathedrals (Fletcher, 1994).

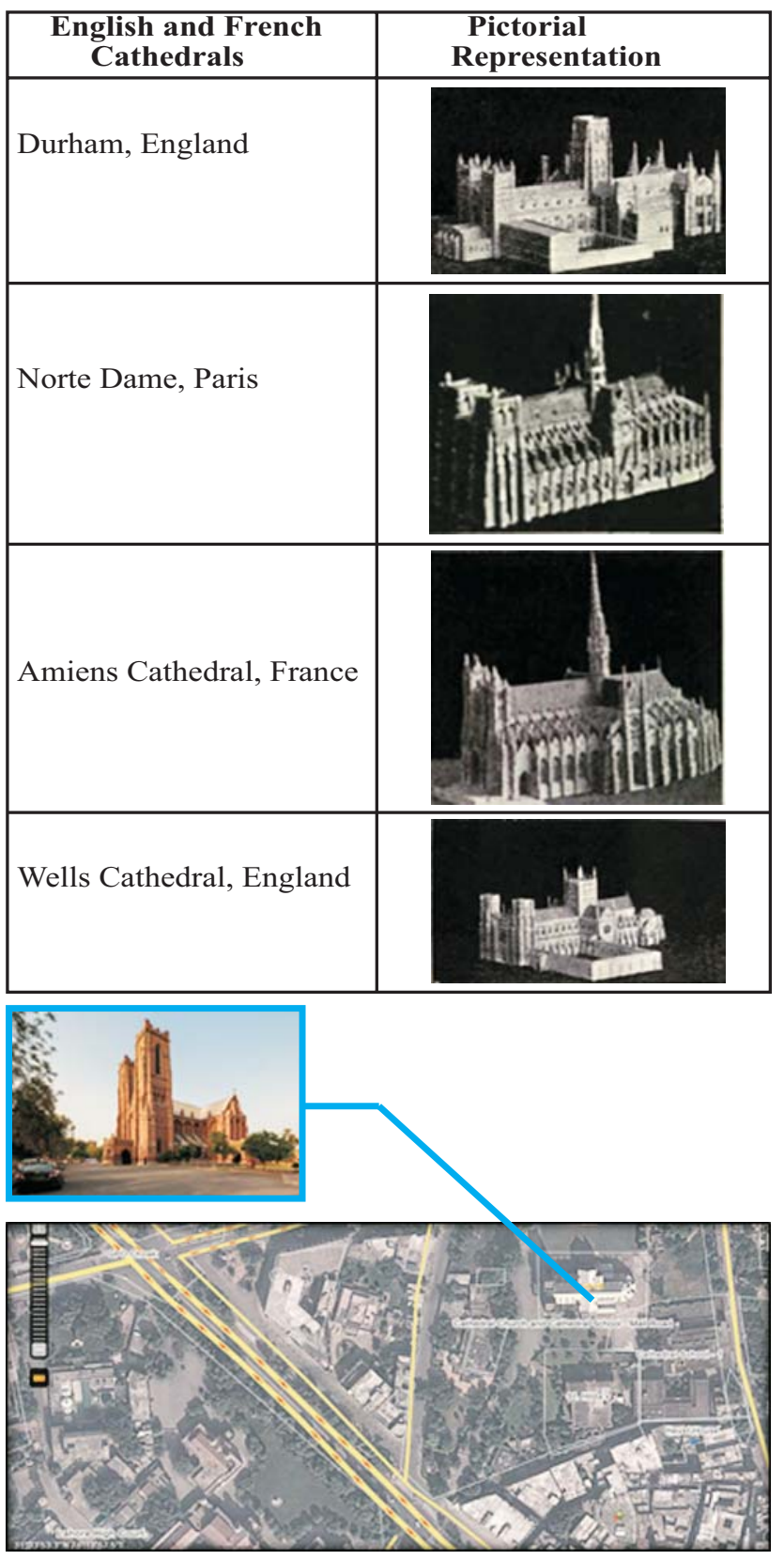

Figure-2: Aerial view of the Cathedral Church of the Resurrection. 
Gothic architectural features. Another example of Gothic Architecture in the sub-continent is the Lady of Dolours Church, located in Thrissur, Kerala, India (Figure 3). This is one of the largest church in India. It was established in 1814, and the existing structure was constructed in 1929. Its interior decorations and paintings are well maintained (Figure 4) (India Opines, 2017).

\section{Urban developments during British Period in Lahore}

Lahore served as the capital of the sub-continent during the Mughal Period. The Mughal kings spent maximum resources on this city and made it grand. In the middle of the eighteenth century the British rulers occupied the city and made many major developments.

Because of its prime location, Lahore received a great deal of colonial attention. New and modern buildings were constructed. Infrastructure was improved. Most of the development during the colonial period took place outside the old fortified city of Lahore. Some of the localities developed during the colonial era are discussed here:

\section{Lahore Cantonment}

The first and foremost development made by the British was the Lahore Cantonment, which was of great significance to the British Army. Barracks were built for British officers and soldiers.

\section{Civil Lines}

As the name implies, Civil Lines was a residential area for civilians. At the time of its development, Civil Lines was a green area of Lahore with low rise bungalows embedded within big lawns, housing the elite.

\section{Saddar}

The word "saddar" in English means "president". Saddar was the head point of Lahore, in the midst of extensive shops
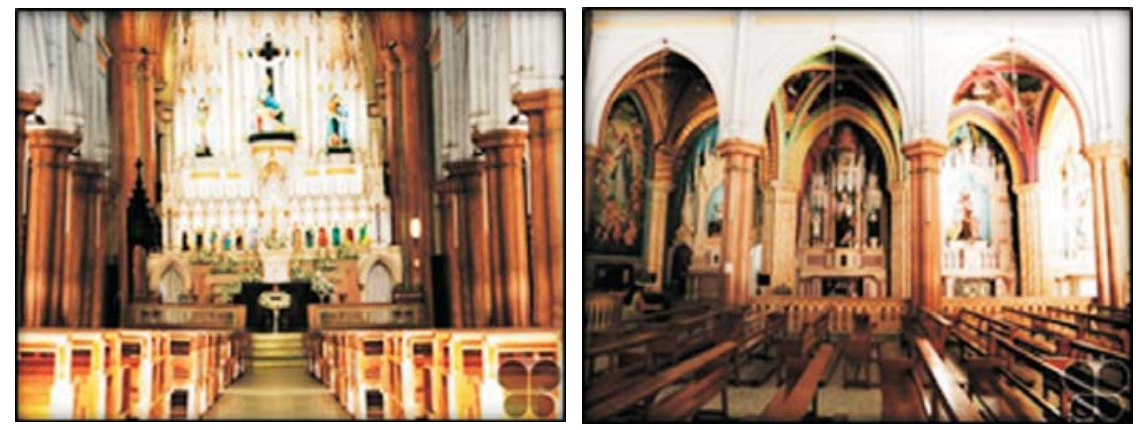

Figure-4: Interior Views of the Lady of Dolours Church, India. and plazas, Saddar during the colonial era was the center of all commercial activities taking place in Lahore.

\section{Mall Road}

Mall Road was a boulevard developed by the British, housing many public structures. The name "Mall Road" is used in many cities today, which were developed in the British era, for example Murree Mall Road, Rawalpindi Mall Road, etc. The British architectural developments of the Anglo-Mughal style can be seen on the Mall Road. Among all these various British constructions is the grand structure of Anglican Cathedral in Neo-Gothic Style.

\section{THE CATHEDRAL CHURCH OF THE RESURRECTION}

\section{Historical Background}

The first cathedral in Lahore was constructed with the permission of Emperor Akbar. In 1595 he approved the construction of a church in close proximity to the fort, but it shut down in 1614, on the order of Emperor Jahangir. At this time, the true representation of the Christian community and their rituals began.

Many British administrators and experts arrived in Lahore during the construction phase of churches and cathedrals. The Cathedral Church of Resurrection was first placed in Anarkali Tomb, but, afterwards, the British constructed this magnificent cathedral at its present location in 1887 .

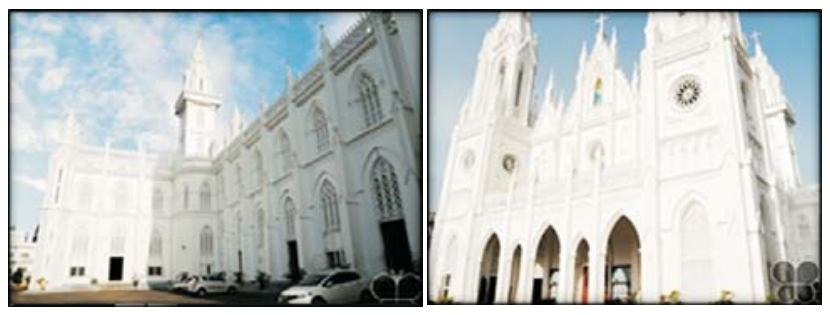

Figure-3: The Lady of Dolours Church, India.

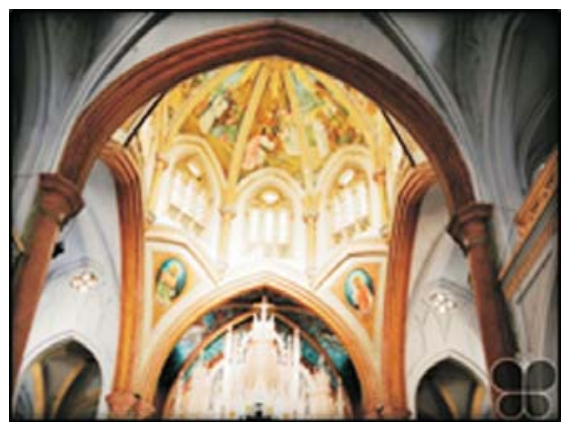




\section{Memorials}

The Christian community claims responsibility for many memorials in the Cathedral because of their ritual importance. They associate the Cathedral with different people. One of the dominating memorials is the ancient Taxila Cross found in 1935 near the site of the ancient city of Sirkap. The Cross is placed on the wall on the north side of the chapel. The structure is also well known for its stained glass windows, pipe organ and a clock manufactured in 1862 (Aijazuddin, 2004). These were gifted by many known people among the Christian community. The Red Cross erected at the Southern lawn of the Cathedral, is the cross put on the roof of the Anarkali Tomb and removed in 1927 and placed here.

The Cathedral is home to some splendid stained-glass window pieces, containing symbolic figures. The glass work on them has been repeatedly appreciated as a rival to the glittering jewel, reflecting the windows of French Gothic Cathedrals. Another window on the western side of the nave is decorated with the traditional lights, which memorialize Bishop Mathew's contributions.

\section{Ownership and maintenance}

All the churches in Pakistan come under the structure of "Churches of Pakistan" (with a total of eight bishops). The Diocese and the Lahore Cathedral come under the "The Lahore Diocese", which covers the areas from Sahiwal to Narowal and Islamabad to Murree. Each Diocese is headed by one bishop and additional priests. Currently, the Lahore Cathedral is headed by Bishop Irfan Jamil and Father Shahid P. Meraj. According to the Bishop and Father until now, the Government of Pakistan has not helped with the maintenance of the Cathedral and the Diocese raises necessary funds for maintenance on its own.

\section{Changes brought to the building structure}

The foundation of the Cathedral was laid in 1874, and the structure was completed in January 1887. However, the two towers with tall spires were added in 1898, (Figure 5). The spires were demolished after the earthquake of 1911 for safety reasons (Figure 6) (Clerkin, 2009).

As a result of the earthquake the roof of the cathedral was damaged and so were the walls and interior of the church, which was re-constructed. This project was executed by the collaboration of two consultants: Civil and Urban Engineers and Pervaiz Vandal and Associates. The renovation project for the roof began on March $14^{\text {th }}, 2005$ and was completed in April 2008 (Church of Pakistan, 2004).

\section{ANALYSIS AND DISCUSSION OF CATHEDRAL CHURCH OF RESURRECTION, LAHORE}

\section{Horizontal Arrangement of the Building}

This Cathedral is a typical Latin cross plan, as depicted in Figure 7, incorporating Gothic revival features having dominant elements of height, pointed arches, flying buttresses, plate tracery, trefoil quartrefoil openings and stained glass windows. The length of the Cathedral in the east-west direction is 226 feet, which includes the 70 feet choir. From the nave to the steps of the choir the distance is 110 feet. The ambulatory of the Cathedral is 15 feet wide. The width of the transepts in a north-south direction, including the porches, is 152 feet (Clerkin, 2009).

\section{Vertical Arrangement of the Building}

The front façade, of the church has Gothic elements like plate tracery, oculus windows, trefoil, quartrefoil openings, flying buttresses and sloping roof, which have been

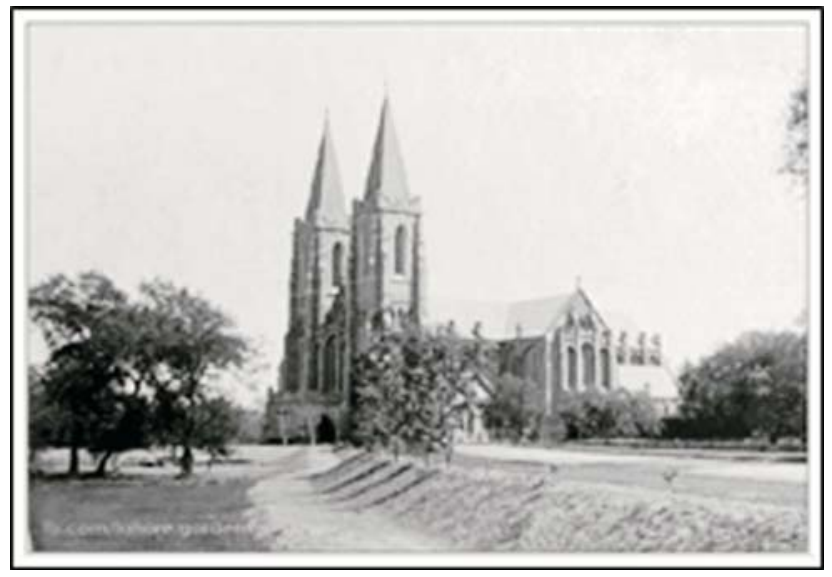

Figure-5: The Cathedral Church of the Resurrrection with Spires.

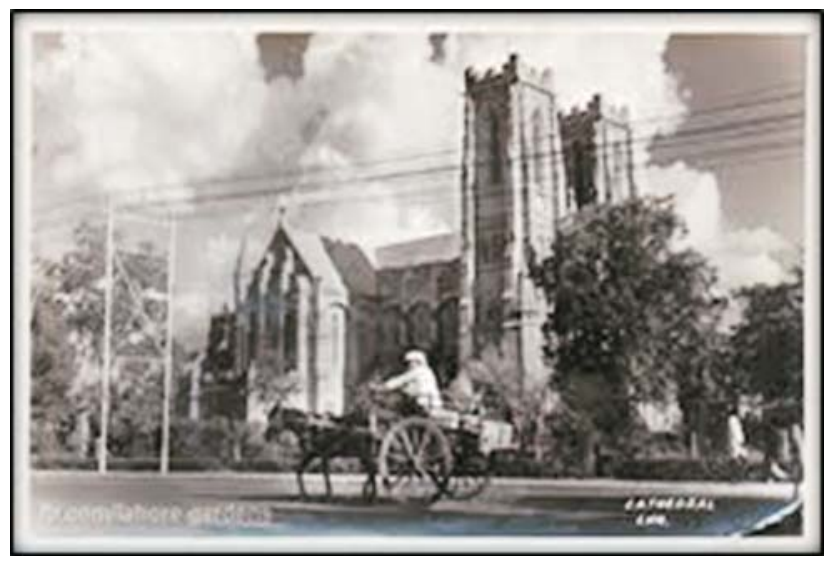

Figure-6: The Cathedral Churchof the Resurrection without Spires. 


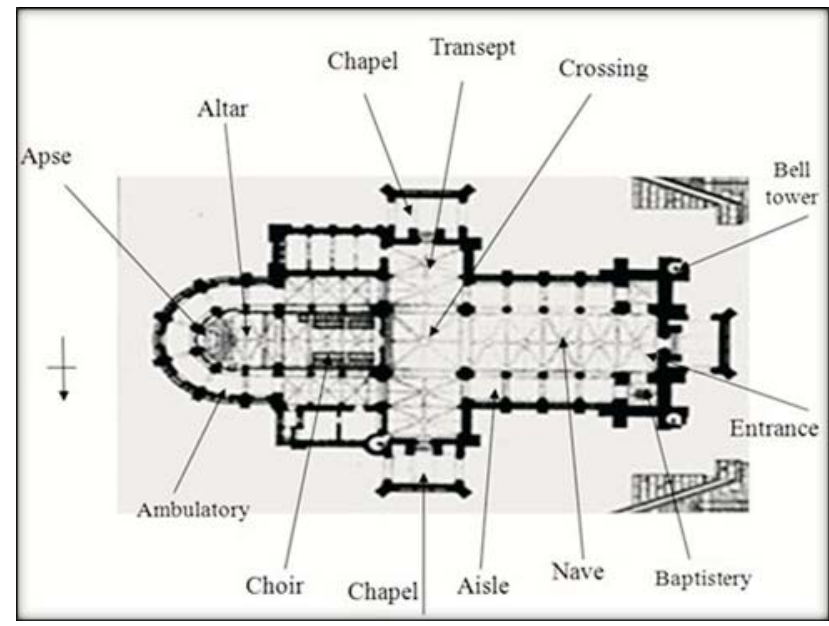

Figure-7: Plan of the Cathedral Church of the Resurrection.

highlighted in Figure 8. The porch, or the entrance portal is 31 feet long. The height of the vault is 65 feet. The maximum existing height of the bell towers is 120 feet. The interior features of importance are the oculus windows with quartrefoil design elements, stained glass windows, and collonettes (Figures 9 and 10).

\section{DOCUMENTATION OF ARCHITECTURAL CHARACTERISTICS}

The architectural analysis of the Cathedral Church of Resurrection highlights those elements that have had major or minor changes done to them with the passage of time.

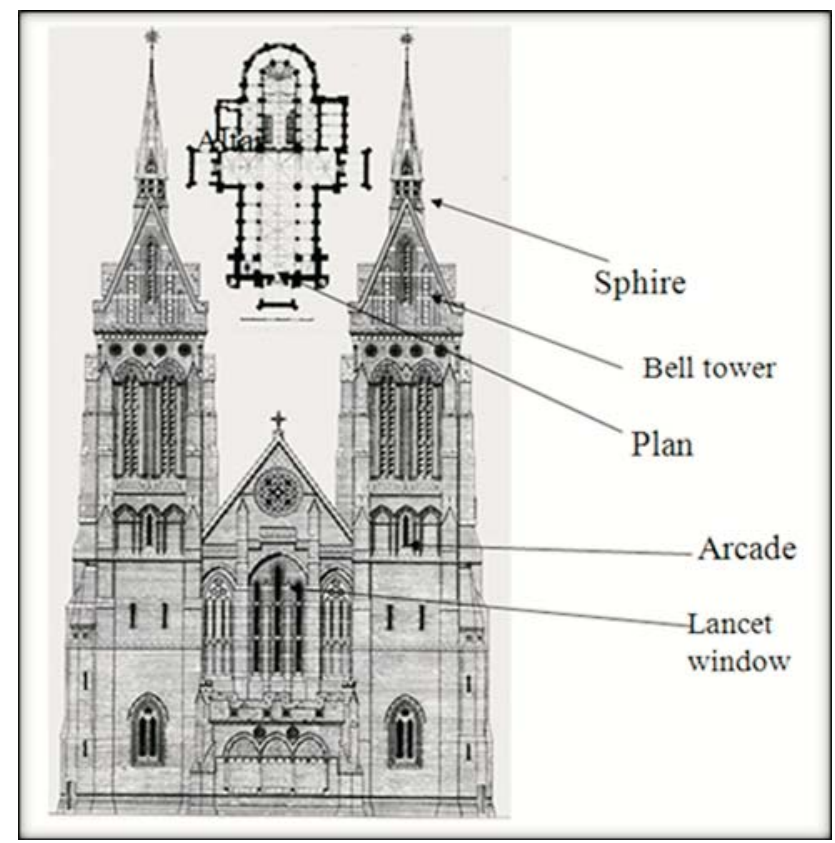

Figure-8: Front Elevation of the Cathedral Church of the Resurrection.
Major features which have changed include interior and exterior walls, entrance portal, the roof, bell towers and other specific features such as the main hall and the orchestra. The reasons for the deterioration of various features of this edifice have been documented (Feilden, 2003).

\section{Walls}

\section{Exterior Walls}

The structure seems to be intact but the brick courses have deteriorated upto three to four feet above ground level. The four-sided views of the Cathedral are shown in Figure 11. The plastered decorative features on the flying buttresses are also in poor condition. These red bricks were prepared from soil specially brought from Jhelum, Pakistan (Aijazuddin, 2004). The plaster was composed of cement and sand.
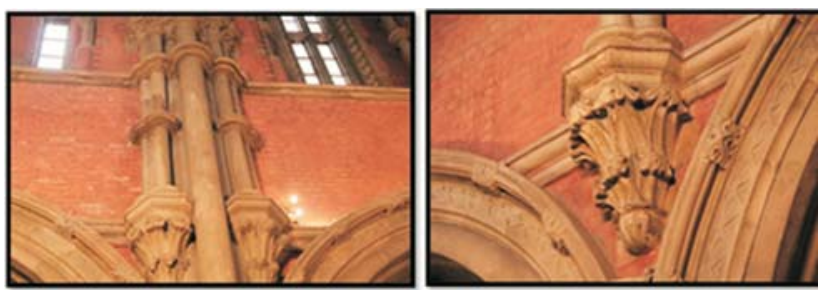

Figure-9: Decorative Collonettes on the Walls around the Nave.

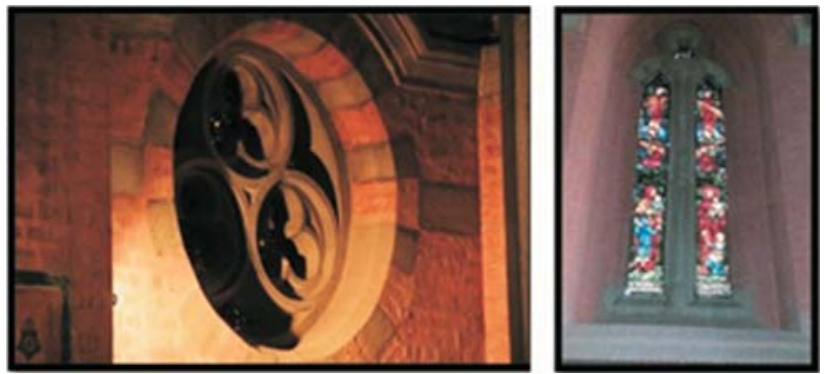

Figure-10: Oculus and Stained Glass Window Openings.
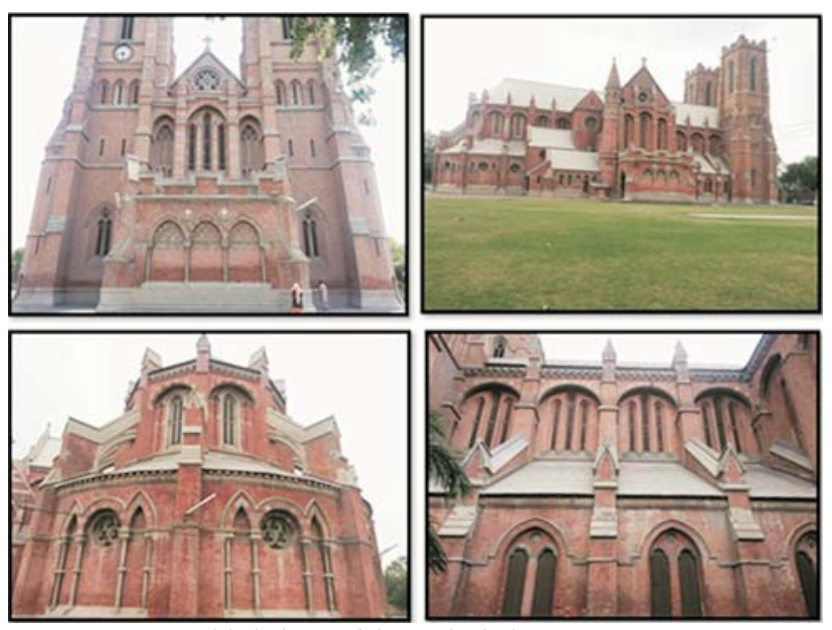

Figure-11: Four-sided views of the Cathedral. 
Figure 12 shows close views of the exterior wall where bricks have deteriorated. Bricks and cornices of the western façade have deteriorated due to dampness. The blind arcade on the western facade of the Cathedral has also been extensively damaged by dampness. The surface bricks and mortar have been strongly affected. Furthermore, on the western façade, the construction steel is exposed in various places.

\section{Interior Walls}

The dampness has affected both the exterior and interior walls which of the Cathedral (Figure 13). The northern aisle's inner surface area where dampness has affected the walls is about three to four feet above the foundation.

\section{Exterior Roof}

The sloping roof is in better condition because it was repaired in 2008. Other surface areas of the roof, including the nave and aisles top covering (barrel vault), side entrances and parapet walls need to be renovated (Figure 14).

\section{Interior Roof}

The interior roof has been conserved using the original materials of construction. The wooden planks require less maintenance. During 2008 conservation of the roof, almost

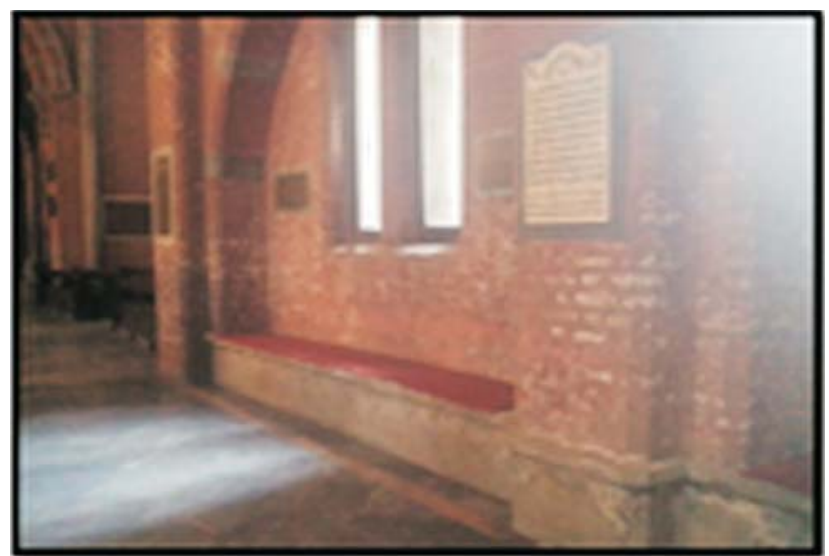

Figure-13: The northern interior wall affected by dampness.
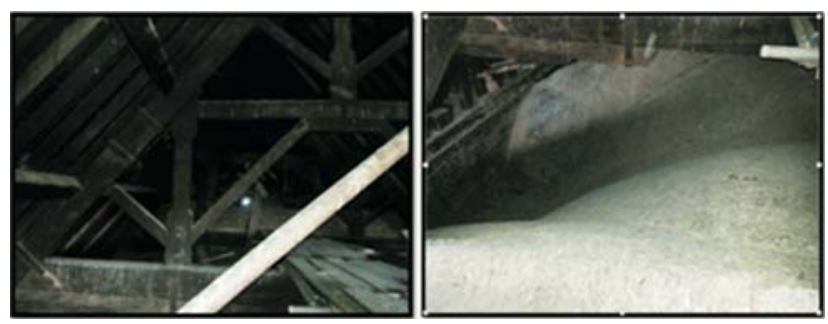

Figure-15: Views of vaults and repaired roof from the northern side access door. all new wood was used, some of the original wooden planks were also reused in this process. This structure seems to be intact now (Figure 15).

Moreover, the inner ceiling of the main hall and entrance portico have been affected by the rain water from the roof (Figure 16). The affected interior and outer areas require conservation before they get further deteriorated. Dampness has caused the bricks to lighten in colour in the walls and vaults of the Cathedral.
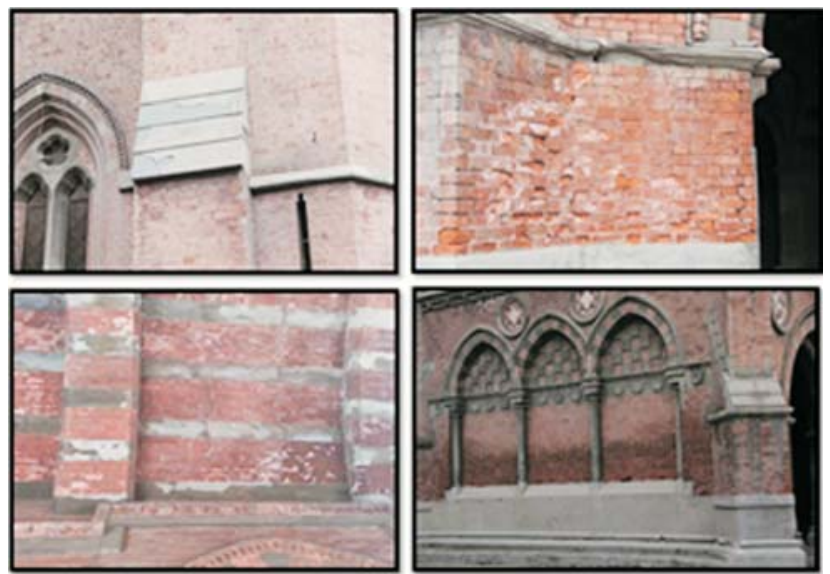

Figure-12: Closer views of exterior affected by dampness.
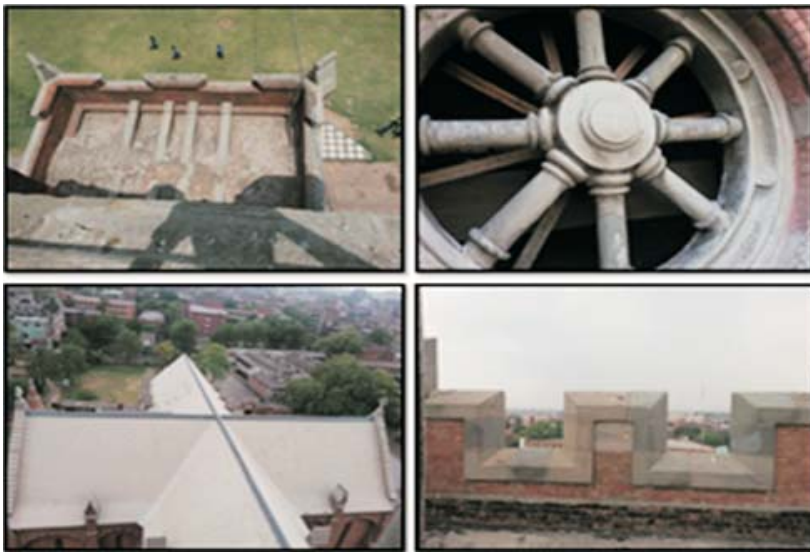

Figure-14: Different views of roof top.
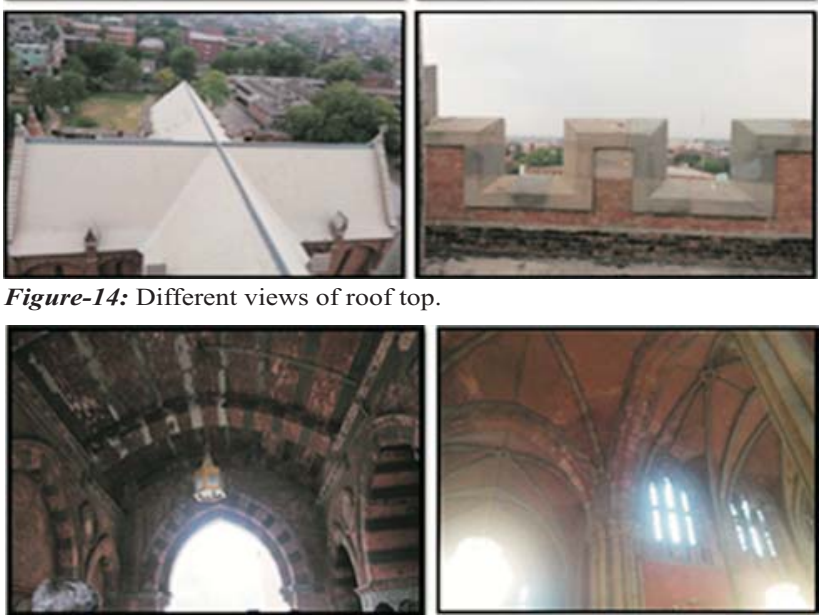

Figure-16: Ceiling of entrance portico and main hall. 


\section{Bell Towers}

\section{Exterior}

As discussed earlier, the bell tower had tall steeples at the top, which were removed after the earthquake in 1911, because of their unstable condition. The existing condition of the tower is shown in Figure 17. From the ground, three feet of the brick foundation has been affected by dampness. The rest of the facade has some minor deterioration in the plastered areas.

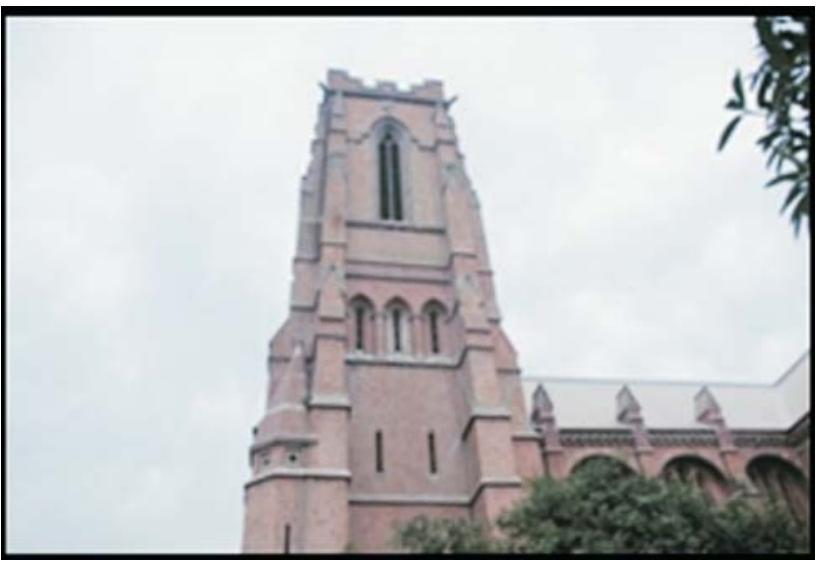

Figure-17: View of the Tower reaching great heights including gothic details of pointed arches, buttresses, trefoil openings, and sloping roof at the rear.
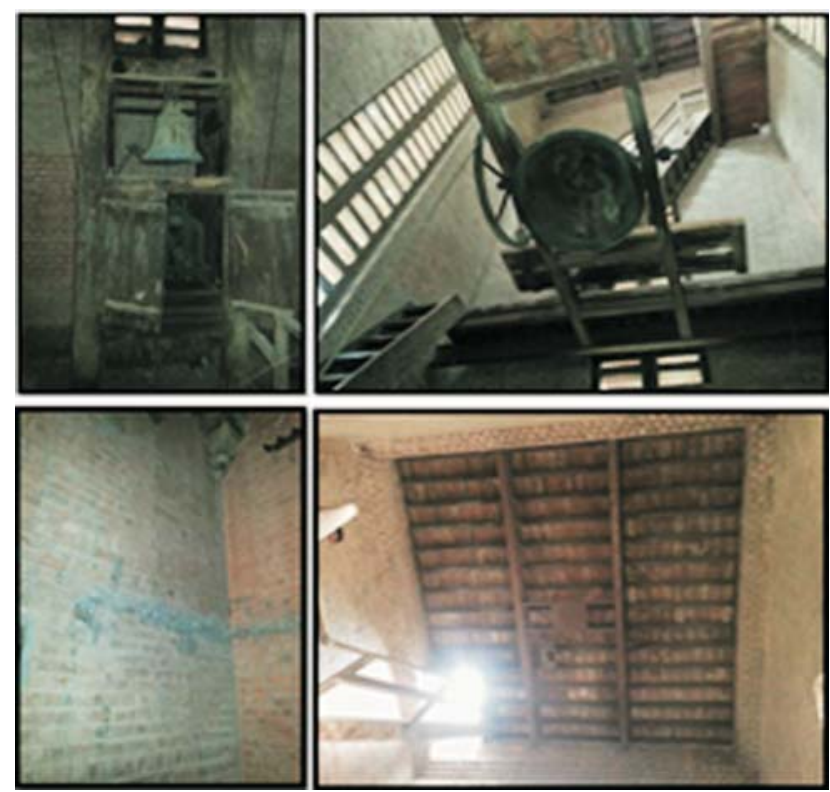

Figure-19: Views of Bell room.

\section{Interior}

Figure 18 shows the stair hall leading to the bells at the top and the approach ladder to the bell tower. The different views of the interior of the bell room at the top of the bell tower are shown in Figure 19. The wall structures are intact; the wooden ladders, approach to the wooden roof and the hanging bells are in good condition. The wooden cabinets are however in poor condition.

\section{Main Hall}

\section{Nave and Aisles}

The main hall consists of a nave with side aisles (Figure 20). This hall is the main area of the Cathedral and shows its grandiosity. Upon entering through the main door, one is stuck by its height and amazing gothic features of arcades, piers, alternations, traceries and stained glass windows.

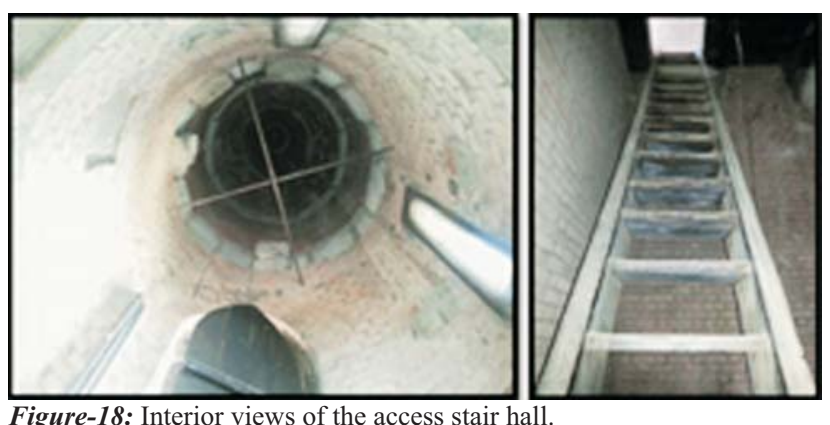

Figure-18: Interior views of the access stair hall.
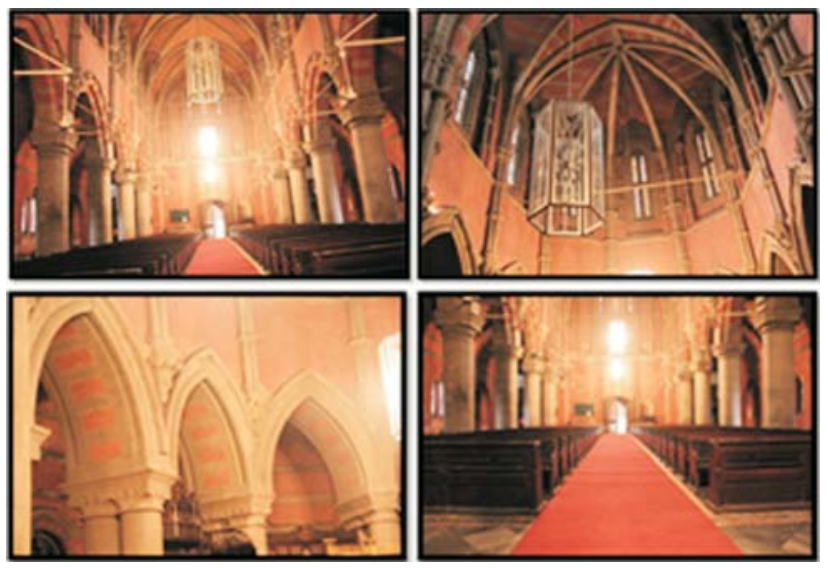

Figure-20: Nave with side aisles of the main hall. 


\section{Altar}

In Christianity, the altar is considered to be the most sacred part of the Cathedral and is used for ritual ceremonies (Watts, 1883). The altar of this Cathedral is located at the eastern half surrounded by an ambulatory (Figure 21). It has a prominent table with golden background containing ritual components.

\section{Orchestra}

This is the most extensively damaged part of the Cathedral. Rain water coming from the damaged roof has ruined the historical orchestra room. Further, the termites have damaged its internal and wooden areas. The floor of the orchestra room is totally damaged due to rainwater and termites. Different views of the orchestra room are shown in Figure 22.

\section{CONCLUSIONS}

On the basic of the documentation and analysis of the Cathedral it can be concluded that the building, which appears to be in sound condition, has many areas that need to be repaired immediately. The significance of its heritage should be of prime importance. The materials to be used for its repair should adhere to the international rules for conservation of monuments. Starting with the walls, serious consideration should be given to the dampness that has affected the walls up to the height of three feet from the ground and further at the edges of the roof. Surface treatment is required and the source of moisture needs to be removed, which can be achieved by water proofing the walls from their base and on the edge of the roof. The plaster of the surface decorations both inside and outside of the cathedral, must also be repaired. The major element of neglect of the Cathedral, that is unique to its own kind, is the Orchestra Room which should be maintained and made operational. It has been ruined by voracious termites. Proper repair and termite treatment will enhance the value of this distinctive
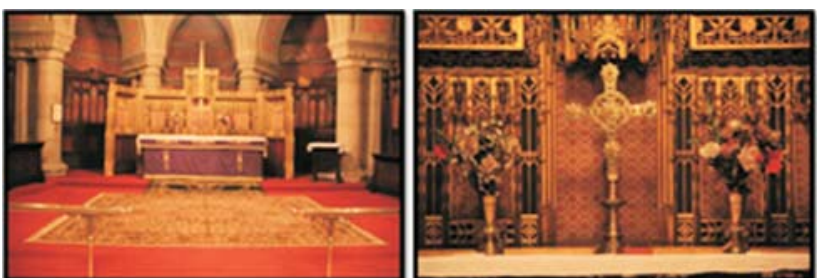

Figure-21: Main altar of the Cathedral.
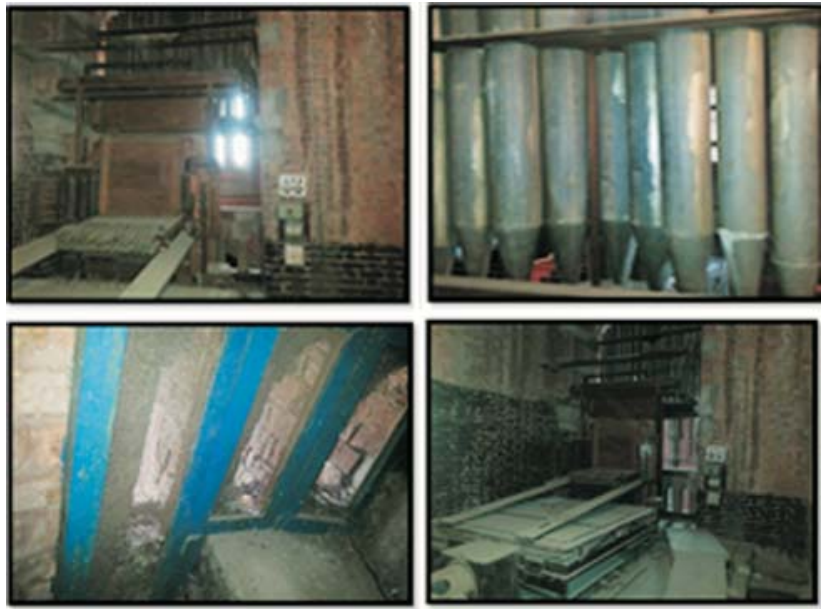

Figure-22: Views of the Orchestra room of the Cathedral.

feature. Another significant element of consideration is the repair and maintenance of the bell towers of the Cathedral. The holes in the walls and broken wire mesh on the windows have enabled birds and pigeons to enter and make their nests, which has affected the building as a whole because their droppings block rainwater pipes and enable grass to grow at certain points on the roof. Bird repellent should be applied on the outer surface of the walls, and the wire mesh of the windows requires immediate repair. The bell room has also been affected by the bird excretions, and the wooden cabinets need to be replaced. Considering the significant heritage of such a unique edifice, its safeguarding will be beneficial for its international recognition.

\section{REFERENCES}

Aijazuddin, F. S., 2004, Lahore recollected, Sang-e-Meel Publishers, Lahore.

2004, Church of Pakistan, 'Repair and Rehabilitation Program', Lahore Diocese, Lahore.

Clerkin, P., 2009, 1880 - "Cathedral Church of Resurrection, Lahore, Pakistan: Architecture of Pakistan - Archiseek Irish Architecture”, viewed 2-6-16, from http://archiseek.com/2009/1880-cathedral-lahore-india. 
Feilden, B. M., 2003, Conservation of historic buildings, Architectural Press, London.

Fletcher, B., 1994, A history of architecture on the comparative method, Bradbury, Agnew, and CO. L1X Printers, London. Glover, W. J., 2011, Making Lahore modern, Oxford University Press, Karachi.

Gosh, A., 2010, The history of architecture, Arise Publishers and Distributors, New Dehli

India Opines, 2017, “14 Most Astonishing Churches in India”, viewed 2-3-2017, form http://indiaopines.com/churchesindia

Morris, J., and Winchester, S., 2008, Stones of Empire, Oxford University Press, Oxford.

Vadakkekara, B., 2007, Origin of Christianity in India, Media House, Delhi.

Watts, J. D., 1883, "Book review: II. Biblical studies: The international standard bible encyclopedia", Review and Expositor, Vol. 4, 446-447.

Wilson, C., 1992, The Gothic Cathedral: The architecture of the Great Church 1130-1530, Thames and Hudson Ltd, London. 